\title{
Managing Pension Obligations in Volatile and Demanding Environments
}

\author{
Patrick Peugeot \\ Chairman and CEO, La Mondiale, 22 boulevard Malesherbes, 75008 Paris, France. \\ E-mail: patrick.peugeot@1amondiale.com
}

The Geneva Papers (2005) 30, 92-94. doi:10.1057/palgrave.gpp.2510016

Keywords: pension reform; French pension system

In France, we are in year one of a new era for the pension market after a year (2002) when corporate pension contracts represented a market of less than 6 billion euros and corporate pension funds were very rare.

So last year, we experienced what so many of us have expected for a long time discussion between employer organizations, employee unions and government, and fortunately it worked. It ended with a new law being very quickly adopted because a political majority closely controls both the National Assembly and the Senate.

The result is that the pay-as-you-go system, which provides 85 per cent of French pensions, is reorganized with three main reforms:

- $\quad$ By 2008, workers and employees in the public sector will be asked to contribute up to the same age as those in the private sector.

- After 2008, a new rule will be applied. The contribution period will be double that of the increase in longevity, which means that at today's pace, two more years of contribution will be needed for each year of increased longevity. It is expected that before 2020, people will retire from work at well over 65 years of age compared to the current retirement age of 57-58 years. In France, as in all European countries, there is a lot to be done to manage those senior employees.

- The system needs to become more balanced by 2020, but the expected improvement of the unemployment rate should balance the results of the system before that time. If that does not work, then we should think about compulsory private pension as mentioned by Dick Harvey.

Compared to the U.S. or U.K., the situation in France is about the same with regard to the decreasing rates and the increasing longevity, but it differs largely if we consider the level of savings. The French economy has one of the highest rates - around 17 per cent - and interestingly, following the very large amount of information that was given by the government to all French citizens (by mail as well as by TV or radio) most French individuals have increased their savings. But, until now, a very small part of it has been invested for pension purposes. The latest information provided by many pools indicates that, even if this rate of savings decreases, the volume dedicated to pensions will increase.

So we have to convince the French people that even if the pay-as-you-go system works, they will need to consolidate their pension with their own investments in 
insurance products. What Dick Harvey said also holds true for France: "Most people need to be either pushed, or pulled, into pension savings through incentives and/or advice".

In our case, the previous government had organized strong tax incentives for private pension systems dedicated to each sector of the economy (agriculture, civil service, self-employed, craftsmen), but it was clearly necessary to build a new product dedicated to private sector employees.

The main objectives of the civil servants involved in the reform were less complex than those mentioned by Fritz von Nordheim: the government wanted transparency, investment in closed funds (the English example was present in the minister's mind) and governance rules to answer to consumer demand.

The result of the first draft presented by the civil service for discussion with the industry was terrible: no one could understand a word of this project. The complexity of the products was so high that the whole industry protested, and the government decided to accept other products to fulfil its objectives. But on the taxation side, the political decision was clear: the incentive had to push the medium-revenue people, whose pension would be the most hit by the evolution of the pay-as-you-go system, to invest in such products. The incentive is proportional to annual revenues with a ceiling of 26,000 euros per year.

Today, shortly after the green light by the government we cannot say much, but it is interesting to see that banks have decided to move strongly in this new market. Most of them have already spent a large amount of money in promotion through TV as well as bill-posting. If we add all the commercial objectives they announced and those published by the insurers, we should have, by the end of 2004, more than 1 million people who have invested in this new product. This figure must be compared to the 2 million people who should really take advantage of the tax incentives. As a poll showed, a great number of young individuals under 40 years of age will have chosen to transfer part of their savings into this product.

There are some problems with investments and advice:

(1) First, investments: The investment policy has not yet been an issue even if the closed fund method is applied in France for the first time in such a way. Insurers are not so optimistic because, with the new accounting rules, most providers will not invest in equities, and we all know what the level of bond rates is today. So it is to be feared that those who choose this product may face disappointment in 3 or 4 years' time.

(2) Second, advice: The need for advice is obvious in so complex a situation. We have in mind the English experience: we do not want to be caught in any case of mis-selling.

This advice requires a high level of expertise. Financial institutions have to be careful in selling the new third-pillar products that have been created (principally the "PERP"). Certainly it cannot be sold like plain-vanilla financial products with shortterm tax benefits, as some could succumb to the temptation.

Expertise is costly and clients have to pay for it. They have to acknowledge it and amortize it over the long term. Financial institutions have an important responsibility 
in educating people about not being obsessed by the day-to-day volatility of the financial markets and the constant benchmarking done between contracts competing on the market.

In France the second pillar, which involves companies, is not developed much in the market and probably will grow slowly. Companies face competition and are under financial constraints. The "Loi Fillon" has created some types of pension funds like the PERE and the PERCO but companies remain free to put them in place or not. In such an environment some nevertheless think that companies could have an important social responsibility in informing their employees about their future pensions. They could open their doors to pension advisors for their employees. We think that this distribution channel can be efficient in helping to address the pension issue in a joint effort with the companies.

To develop this second pillar, insurance companies should be able to convince French corporations that they can be their best partners in managing their social liabilities. There is still much room for development if insurance companies put in place some kind of asset and liability management techniques.

And finally, some precautions have to be taken, especially in the relationship with the State:

- Insurance companies are large institutional investors that can be seen as "deep pockets" ready to help the State "fill the gap" in various sectors. For example, today, the French government is studying curious ideas, such as compelling French insurance companies to invest more heavily in venture capital, forgetting that it may be counter-productive and a serious attack against the free investment decision of providers.

- Last but not least, insurers must protect their profitability in this new market. Insurance margins are today generally recovering. Insurers have to remain sensible and not take excessive risks in the life market over the long term and they have to fight to remain free regarding costs. This is why, for example, we would like the 1 per cent world (even the 1.5 per cent one) to not cross the Channel!

In conclusion, it is a new era because we have no experience of such products, but we think French insurers are able to take advantage of all the experience of our foreign colleagues who have faced such problems as the volatility of investments and increasing longevity. It is a great risk, but it may be a nice opportunity for new profits for our insured members and/or our shareholders. 